\title{
Relationships Among Personality, Situational Construal and Social Outcomes
}

\author{
PATRICK J. MORSE* ${ }^{*}$ KYLE S. SAUERBERGER, ELYSIA TODD and DAVID FUNDER \\ Department of Psychology, University of California, Riverside, Riverside, CA, USA
}

\begin{abstract}
The present study demonstrates a novel way of exploring the relationship between personality and social outcomes by examining an understudied intermediate step: situational construal. Construal is assessed in terms of the degree to which one's description of a situation agrees with others' descriptions of the same situation (normativity) and the degree to which the description is positively valenced. Participants $(N=256)$ provided information about their personality and subsequently used the Riverside Situational $Q$-sort to describe their construal of three in-lab interactions with unacquainted others. A measure of positive behavioural social outcomes was constructed from observer ratings of the video-recorded interactions. Extraversion, agreeableness, openness and neuroticism (negatively) were related to positive behavioural social outcomes, as well as to normativity and positivity of construal. Additionally, normativity and positivity of construal were related to positive social outcomes. However, mediation analyses did not confirm that construal mediates the relation between personality and positive social outcomes. Copyright (C) 2015 European Association of Personality Psychology
\end{abstract}

Key words: personality; situations; situational construal; social outcomes

Personality has important associations with individual, interpersonal and institutional outcomes (Ozer \& Benet-Martínez, 2006; Roberts, Kuncel, Shiner, Caspi, \& Goldberg, 2007). For example, at the individual level, happiness, subjective well-being, health and longevity, and psychopathology are all linked to various Big Five traits (Ozer \& Benet-Martínez, 2006). At the institutional level, occupational choice, political values, community service and criminality are all associated with this same set of traits.

The focus of the present research is personality's relations to social or interpersonal outcomes or constructs that involve others. Ozer and Benet-Martínez (2006) suggest that extraversion is the personality trait most relevant to the prediction of social outcomes, and a wide range of research supports this claim. Extraversion has been linked to likability in interactions with unacquainted others (Back, Schmukle, \& Egloff, 2011), likability in online social networks (Stopfer, Egloff, Nestler, \& Back, 2013), popularity among adults (Paunonen, 2003), social status (Anderson, John, Keltner, \& Kring, 2001), social well-being (Hill, Turiano, Mroczek, \& Roberts, 2012) and relationship satisfaction (Schaffhuser, Allemand, \& Martin, 2014). Aside from extraversion, neuroticism has been linked to poorer social outcomes, such as a lack of closeness with others (Berry \& Hansen, 1996), relationship dissatisfaction (Finn, Mitte, \& Neyer, 2013; Schaffhuser et al., 2014), lower social well-being (Hill et al., 2012) and lower social status (for men only; Anderson et al., 2001), and agreeableness has been linked to relationship satisfaction (Schaffhuser et al., 2014) and social well-being (Hill et al., 2012).

*Correspondence to: Patrick J. Morse, Department of Psychology, University of California, Riverside, 900 University Ave, Riverside, CA 92521, USA.

E-mail: patrick.morse@email.ucr.edu
However, research is generally lacking concerning the processes by which personality has bearing on social outcomes such as these. Accordingly, the purpose of the present paper is to explore one possibility for an intermediate step between personality and social outcomes. Among other examples presented in this special issue, oral fluency has been found to partially mediate the relationship between extraversion and popularity among 7- and 8-year-old children (Ilmarinen, Vainikainen, Verkasalo, \& Lönnqvist, 2015), and emotion regulation and positive interpersonal behaviour in interactions between relationship partners have been found to partially mediate the relationship between personality and long-term relationship satisfaction (Vater \& Schröder-Abé, 2015).

We contribute to these findings by proposing an additional intermediate step between personality and social outcomes. This step is construal, which is an individual's perception of a situation. According to the Situational Construal Model (Funder, 2013, July), construal is proposed to be a function of both one's personality and the situation in which one finds himself or herself, and it is assumed to affect one's behaviour in that situation. For example, an extravert may construe a typical social gathering as enjoyable and thus become likely to behave in a talkative and gregarious manner, resulting in desirable social outcomes, whereas an introvert may construe the same situation as unpleasant and thus behave in a constrained and awkward manner, limiting the likelihood of social success.

The general idea of situational construal can be traced as far back as Murray (1938), who asserted that an individual's perception of a situation is determined both by objective characteristics of the situation and by characteristics of the person who perceives it. However, research on situational 
construal is still very much in its nascent stages, and there is no widely agreed-upon approach for defining or calculating it. Previous research has considered both the extent to which people view situations distinctly from how others construe them, which can be termed distinctiveness of construalthe inverse of which is normativity of construal-and the extent to which people view situations positively or negatively, which can be termed valence of construal. The normativity of construal is not to be confused with the concept of profile normativeness in research on the profile accuracy of personality judgements (Biesanz, 2010; Furr, 2008). Normativity of construal reflects the extent to which an individual construes a situation similarly to others in the same situation, whereas profile normativeness reflects the extent to which one's personality profile matches a group's average personality profile. Aside from this distinction, the construal of situations appears similar to the perception of persons in that both consist of actor and target effects - an actor's perception of a target's personality is made up of, in part, the actor's general perceptions of others (actor effects) and others' general perceptions of the target (target effects; Kenny, 1994), just as one's construal of a situation is made up of how the actor construes a situation and how the situation is generally construed by others. If the normativity and valence of one's construal are consistent across situations, these constructs would be conceptually parallel to actor effects in the person perception literature (Kenny, 1994). Furthermore, just as the perception of an individual is related to subsequent behaviour towards that individual (Kelly, 1950), situational construal is proposed to be related to behavioural outcomes.

This suggests that person perception and situational construal may consist of similar perceptual processes, but research has yet to explore the extent of those similarities. Rather, the focus of situational construal research, to date, first deals with understanding the definition and correlates of the construct. In one study, neuroticism and openness were found to be related to the distinctiveness of construal of Thematic Apperception Test (TAT) cards, such that those higher in neuroticism construed TAT stimuli as more upsetting, threatening and frustrating than those lower in neuroticism and those higher in openness construed the same stimuli as more humorous, intellectual and complex than those lower in openness (Serfass \& Sherman, 2013). In a more naturalistic setting, personality was again found to be related to the distinctiveness of construal of situations experienced in everyday life (Sherman, Nave, \& Funder, 2013). Individuals higher in agreeableness construed their situations as higher in cooperation and communion than those lower in agreeableness and those higher in conscientiousness construed their situations as more relevant to success and work than those lower in conscientiousness (Sherman, Nave, $\&$ Funder, 2013). As yet to be determined, and to be explored here, is how personality is related to the extent to which situations are construed similarly by people in the same situation (i.e. normativity of construal). Additionally, the present work extends previous research by considering not only the relationship between personality and construal but also the relationship between construal and social outcomes.
Elsewhere, construal has been considered in terms of valence. Morse, Sweeny, and Legg (2015) considered the extent to which participants perceived their specific experiences with health care positively or negatively and assessed how this construal was related to personality and health outcomes, such as patient satisfaction and adherence. The study found that participants higher in conscientiousness, agreeableness and extraversion construed their healthcare situations more positively than those lower on these traits, and those higher in neuroticism construed their healthcare situations more negatively than those lower in neuroticism. Additionally, valence of construal was found to be related to health outcomes following these healthcare situations, such that participants construing their visit more positively reported better health outcomes than those construing their visit more negatively.

These studies highlight the influence of personality on construal, but each also illuminates the strong role of actual situation content (Morse et al., 2015; Serfass \& Sherman, 2013; Sherman, Nave, \& Funder, 2013). Slightly less clear is the extent to which construal is related to situational outcomes because the assessment of outcomes is not yet common practice. The research conducted by Morse and colleagues is an exception, as is the more specific exploration of the role of a construal-like construct mediating the relationship between personality and relationship satisfaction (Finn, Mitte, \& Neyer, 2013). Finn et al. (2013) considered the mediating role that information processing plays in the relationship between neuroticism and relationship dissatisfaction and found that the relationship between these two variables can be explained in part by the negatively biased processing of ambiguous information, a process not unlike situational construal.

To our knowledge, this will be the first study to explore the relationships among personality, construal and social outcomes. First, we hypothesize that personality-extraversion, agreeableness and neuroticism in particular-is related to social outcomes. Second, we hypothesize that personality is related to situational construal, in terms of both its normativity and positivity. Third, we hypothesize that each definition of situational construal is related to social outcomes. Fourth, we hypothesize that situational construal will mediate the relationships between personality and social outcomes.

In order to assess these hypotheses, we had participants take part in a multi-visit study in which they described their personality, interacted with unacquainted others in three different situations, described these situations and subsequently had their socially relevant behavioural outcomes rated by trained observers. These data allow for a novel exploration of the relationships among personality, situational construal and social outcomes.

\section{METHOD}

\section{Participants}

The sample consisted of 256 undergraduate students from the University of California, Riverside, who were recruited from an online psychology research participation system to 
participate in this multi-visit study. Participants were scheduled to complete four visits in the lab and were compensated with research credit and up to $\$ 115$ for the completion of all visits and bonuses associated with certain visits. Consistent with the diversity of the University of California (UC) Riverside's undergraduate population, the sample was 48.8\% Asian, 23\% Hispanic/Latino, 8.2\% Caucasian, $4.3 \%$ Middle Eastern, $3.1 \%$ African American and $12.5 \%$ other. The sample consisted of 130 women and 126 men, and the average age was 19.83 years $(S D=1.25)$.

\section{Procedures}

Participants completed four visits to the lab, which were each spaced roughly 1 week apart. During the first visit, participants were provided with information about the study, answered demographic questions and completed the Big Five Inventory (BFI; John, Donahue, \& Kentle, 1991; John, Naumann, \& Soto, 2008) to describe their personality. In the present sample, the BFI demonstrated good reliability (extraversion: $\alpha=.86$; agreeableness: $\alpha=.74$; conscientiousness: $\alpha=.81$; neuroticism: $\alpha=.85$; and openness: $\alpha=.74$ ).

In Visits 2-4, participants were assigned to interact with two other participants with whom they were unacquainted; these unacquainted triads changed every visit, such that participants never interacted with the same partners more than once. Visit 2 was an unstructured interaction, in which participants were seated, invited to talk about 'whatever you like' and left alone for 5 minutes. Visit 3 was a cooperative task, in which each participant was rewarded with a $\$ 5.00$ bonus if the triad completed a specified tinker-toy model within a 5-minute time limit. Visit 4 was a competitive task, in which participants played several rounds of the sound-repetition game 'Simon' and the overall winner received $\$ 5.00 .^{1}$

Following each visit, participants completed the Riverside Situational Q-sort (RSQ; Wagerman \& Funder, 2009) to describe their impression of the situation they experienced. The Q-sort methodology is a forced-choice assessment that results in a quasi-normal distribution of ratings, such that fewer items can be placed in more extreme categories. The RSQ is an 89-item measure of the psychological properties of situations (e.g. 'A job needs to be done'), and participants rated the extent to which each item was characteristic of their situation $(1=$ not at all characteristic, $9=$ extremely characteristic). Upon completion of all four visits, participants were debriefed and paid for their participation.

\section{Behavioural assessment procedures}

In order to assess participants' social outcomes, we video recorded each interaction, and research assistants subsequently assessed participant behaviour using the Riverside Behavioral Q-sort (RBQ; Funder, Furr, \& Colvin, 2000). The RBQ uses the same format as the RSQ except that it contains 68 items that describe behaviour (e.g. 'Laughs frequently'). In order to assess participant behaviour, research

${ }^{1}$ These three situations experienced by each participant are variously referred to in this article as 'situations', 'interactions', 'sessions' and 'visits'. assistants watched a full 5-minute interaction among three participants and then rated the behaviour of one participant in the triad using the RBQ. Each participant was viewed and assessed by four unique research assistants for each of their visits, and these research assistants were assigned such that they never assessed the behaviour of the same participant more than once, nor did they even observe an interaction involving any participant whose behaviour they already assessed. Additionally, the research assistants did not assess the behaviour of any participant they knew outside of the lab context. This care ensured that observation of a participant in one interaction would not influence the behavioural assessment of that participant in any other interaction, nor would prior knowledge of the participant influence the assessment of his or her behaviour. Additionally, the research assistants were staggered such that they were assigned to different groups of four raters across participants and interactions. Ultimately, the research assistants demonstrated good reliability in their assessment of participant behaviour (mean $\alpha=.80$ ). However, if the reliability among the four coders of a particular video fell below $\alpha=.70$, which occurred for about $20 \%$ of the videos, the research assistant who deviated most from the other three recoded the participant's behaviour upon re-watching the video of his or her interaction.

Note that the three central variables in this study, personality, situational construal and social outcomes, were assessed on the basis of three distinct sources of data. Personality was assessed via self-report; situational construal was assessed via similarity between each participant's situational description and descriptions provided by others (or a positivity template, see succeeding sections); and behavioural outcomes were assessed via observer ratings of the video-recorded interactions. Thus, the relationships reported in the succeeding sections are unlikely attributable to shared method variance, a common concern when participants' self-reports are the sole source of data (Arnulf, Larsen, Martinsen, \& Bong, 2014; Baumeister, Vohs, \& Funder, 2007).

\section{RESULTS}

\section{Hypothesis 1: Personality and social outcomes}

The first step in the analyses was to construct a measure of positive behavioural social outcomes. The measure is a composite of six RBQ items that are self-evidently relevant: 'exhibits social skills', 'seems to like other(s) present', 'exhibits an awkward interpersonal style (R)', 'seems likable', 'keeps other(s) at a distance; avoids development of any sort of interpersonal relationship (R)' and 'seems to enjoy the situation'. After research assistants completed the behavioural coding described earlier, we calculated the social outcomes score for each participant for each visit by averaging their scores on the six items (after reverse scoring the appropriate items) across the raters. This measure of social outcomes was reliable at each visit (unstructured: $\alpha=.81$; cooperative: $\alpha=.82$; competitive: $\alpha=.85$; mean $\alpha=.83$ ). This process resulted in one social outcomes score for each participant at each visit, for a total of three 
outcomes scores for each participant. Across visits, this outcomes measure was reliable $(\alpha=.73)$, indicating that social outcomes were consistent across the three situations experienced by each participant.

In order to obtain a sense of the broad relationships between personality and social outcomes across situations, we combined participants' three outcomes scores and correlated that average with their self-rated BFI. The findings (Figure 1) were consistent with prior research: extraversion and agreeableness were positively related to social outcomes, $r(237)$ $=.45, p<.01,95 \%$ CI $[0.34,0.54]$ and $r(237)=.18$, $p<.01,95 \%$ CI $[0.05,0.30]$, respectively, whereas neuroticism was negatively related $r(237)=-.13, p=.05,95 \% \mathrm{CI}$ $[-0.25,0.00]$. We conducted these same analyses for each visit, and this pattern of results was consistent across visits, although some visit-specific relationships were nonsignificant (Figure 1).

\section{Hypothesis 2: Personality, normativity of construal and positivity of construal}

Next, we explored the relationships between personality and situational construal, in terms of both normativity and positivity. Normativity of construal, or the extent to which an individual construes a situation similarly to others experiencing the same situation or a similar situation, was calculated in two ways. In the first approach, we correlated each participant's RSQ of a particular interaction with the mean of all participants' RSQs of the same type of interaction (e.g. the unstructured interaction). In the second approach, we correlated each participant's RSQ of a particular interaction with the mean of the RSQs completed by the two partners within each of his or her particular triads.

Although in principle these two ways of measuring normativity are distinct, in the present data, they were nearly equivalent. The two normativity scores were highly correlated across visits, $r(237)=.84, p<.01,95 \%$ CI [0.80, 0.87], and within each visit [unstructured: $r(230)=.77, p<.01$, 95\% CI [0.72, 0.81]; cooperative: $r(229)=.72, p<.01,95 \%$ CI $[0.66,0.77]$; and competitive: $r(229)=.72, p<.01,95 \%$ CI $[0.66,0.77]]$. Additionally, the two approaches demonstrated a consistent pattern of findings across analyses. For the sake of completeness, results using both methods will be reported; the first method will be referred to as the 'all participants' normativity score, and the second method will be referred to as the 'interaction partners' normativity scoredescribing, in each case, the group with which each participant's RSQ is compared. Both scores were reliable across the three visits (all participants $\alpha=.76$; interaction partners $\alpha=.61$ ), demonstrating that participants who construed one situation normatively, by either definition, also tended to construe their other situations normatively.

In order to provide a sense of the broad relationships between personality and the normativity of construal across situations, we combined participants' normativity scores across visits and correlated the average with their self-rated BFI; we also correlated their self-rated BFI with normativity scores within visits. Figure 2 shows the results. While most of the effect sizes were small and did not individually attain conventional statistical significance, the overall pattern was visible, clear and consistent for three of the Big Five traits. Extraversion and openness were generally positively related to normativity, and neuroticism was negatively related. While agreeableness was somewhat positively related to normativity and conscientiousness was somewhat negatively related, these latter results were weaker and less consistent. These results provide some support for our second hypothesis: Personality is consistently related to the normativity of construal, although these effects are small. For example, the largest effect was found between neuroticism and

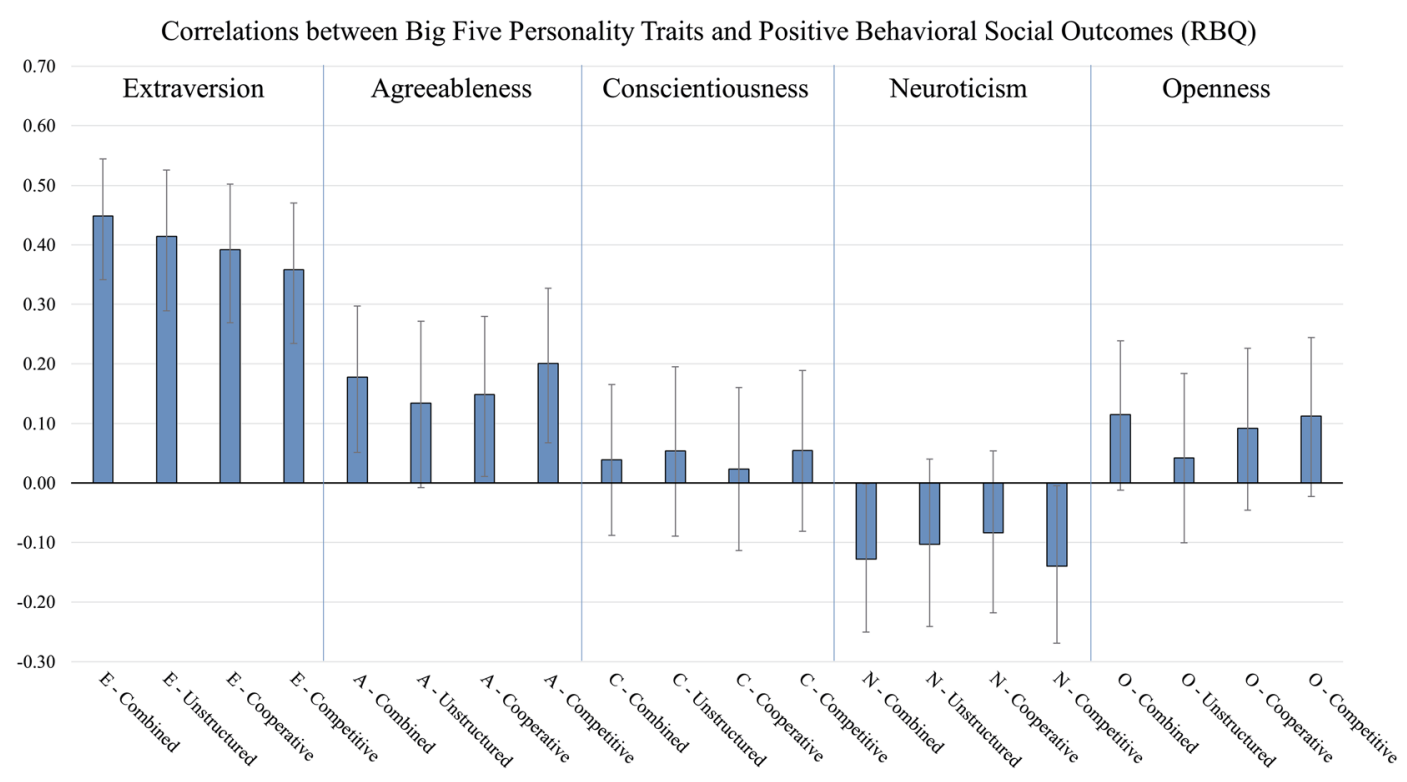

Figure 1. Correlations between Big Five personality traits and observer-rated positive behavioural social outcomes are presented for the interactions combined $(n=239)$ and for each of the unstructured $(n=190)$, cooperative $(n=205)$ and competitive $(n=211)$ interactions. Ninety-five per cent confidence intervals are represented in the figure. 
Correlations between Big Five Personality Traits and Normativity of Construal (RSQ)

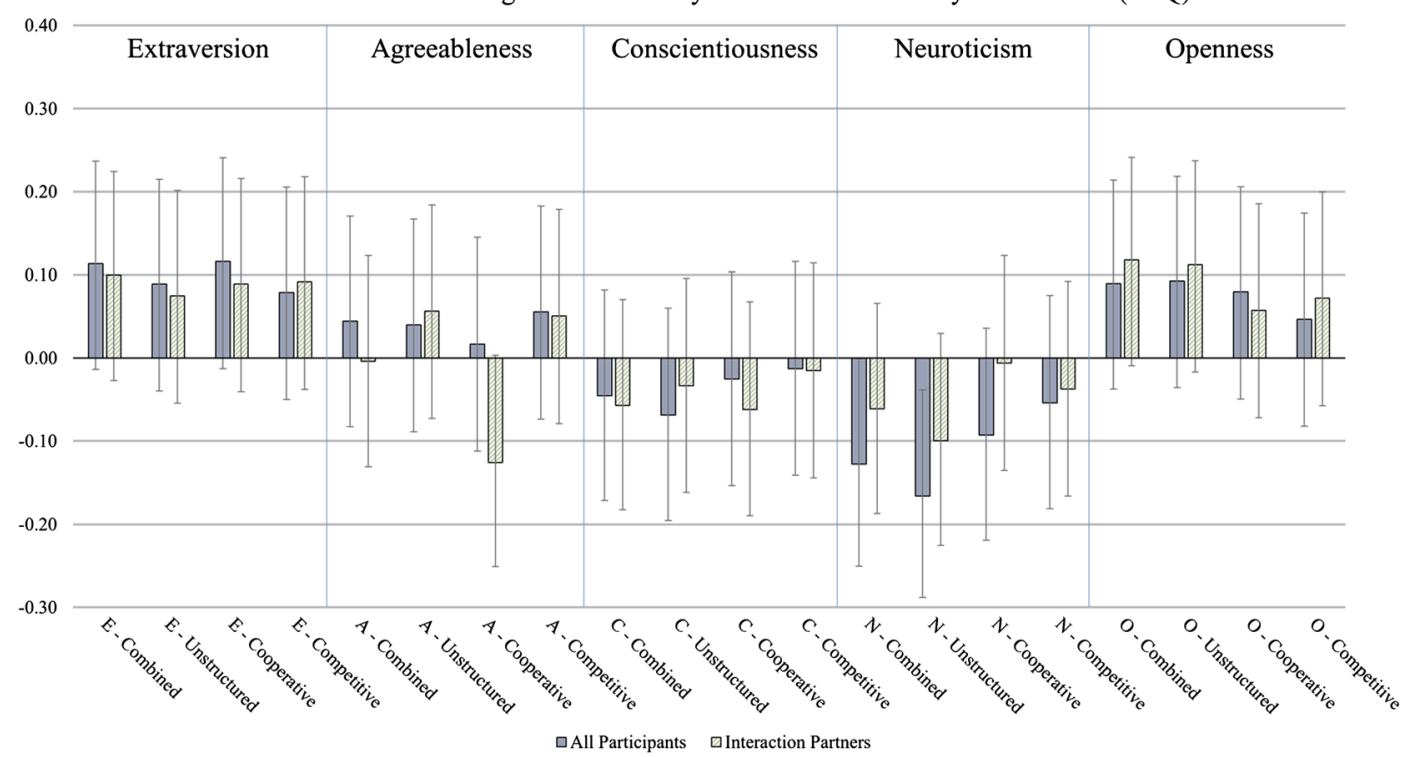

Figure 2. Correlations between Big Five personality traits and normativity of construal are presented for the interactions combined ( $n=239)$ and for each of the unstructured $(n=234)$, cooperative $(n=233)$ and competitive $(n=233)$ interactions. Normativity was calculated both in relation to all participants in the same situation and in relation to the two interaction partners in each individual's triadic interaction. Ninety-five per cent confidence intervals are represented in the figure.

normativity in the unstructured interaction as calculated in relation to all participants in that interaction, $r(232)=-.17$, $p=.01,95 \%$ CI $[-0.29,-0.04]$.

We next explored the relationships between personality and positivity of construal. Research assistants used the Qsort method to rate the degree to which each RSQ item was characteristic of a positive situation. These ratings were highly reliable $(\alpha=.96)$, and we averaged the research assistants' ratings of each of the items, creating an 89-item positivity template. We correlated each participant's RSQ for each visit with the positivity template (i.e. the 'Positivity Template Match' approach), resulting in three positivity of construal scores for each participant, which were consistent across visits $(\alpha=.64)$, indicating that participants who construed one situation positively also tended to construe the other two situations positively.

In order to obtain a sense of the broad relationships between personality and positivity of construal, we combined participants' 'Positivity Template Match' scores for the three interactions and correlated that average with their self-rated BFI. Additionally, to respond to the fact that the average description of all situations, across participants, tends to be mildly positive, we partialled out normativity, or the degree to which each participant's RSQ matched that of other raters of the same situation, when correlating positivity with personality. It will be recalled that this 'normativity' rating was calculated in two ways - one in relation to all participants in the same type of interaction (e.g. the unstructured interaction) and the other in relation to the two other members of each participant's individual triad—and both normativity scores were partialled out of the correlations between positivity of construal and personality. Although the results are nearly identical across all three approaches, for completeness, we report all relationships between personality and positivity of construal in Figure 3. Positivity was significantly related to extraversion [positivity template match: $r(237)=.17, p<.01,95 \%$ CI $[0.04,0.29$; positivity relative to all participants: $r(236)=.14, p=.04$, $95 \%$ CI $[0.01,0.26]$; positivity relative to triad partners: $r(236)=.15, p=.02,95 \%$ CI $[0.02,0.27]]$, agreeableness [positivity template match: $r(237)=.16, p=.02,95 \% \mathrm{CI}$ $[0.03,0.28]$; positivity relative to all participants: $r(236)=.15, p=.02,95 \%$ CI $[0.03,0.27]$; positivity relative to triad partners: $r(236)=.17, p<.01,95 \%$ CI $[0.04$, 0.29 ] , openness [positivity template match: $r(237)=.11$, $p=.08,95 \%$ CI $[-0.01,0.24]$; positivity relative to all participants: $r(236)=.08, p=.20,95 \%$ CI $[-0.04,0.21]$; positivity relative to triad partners: $r(236)=.08, p=.23,95 \%$ CI $[-0.05,0.20]]$ and neuroticism [positivity template match: $r(237)=-.27, p<.01,95 \%$ CI $[-0.39,-0.15]$; positivity relative to all participants: $r(236)=-.24$, $p<.01,95 \%$ CI $[-0.36,-0.12]$; positivity relative to triad partners $r(236)=-.27, p<.01,95 \%$ CI $[-0.38,-0.15]]$. Conscientiousness did not appear to be related to positivity. Whereas individual results did not attain traditional statistical significance in every instance, the overall pattern is clear and consistent across visits, as can be seen from Figure 3. In sum, participants who were more extraverted, agreeable and open, and less neurotic, tended to construe their interactions more positively both overall and in relation to other participants.

\section{Hypothesis 3: Normativity of construal, positivity of construal and social outcomes}

Next, we examined the relationships between our two construal terms. Across visits, the positivity of construal was generally correlated with normativity, whether normativity 
Correlations between Big Five Personality Traits and Positivity of Construal (RSQ)

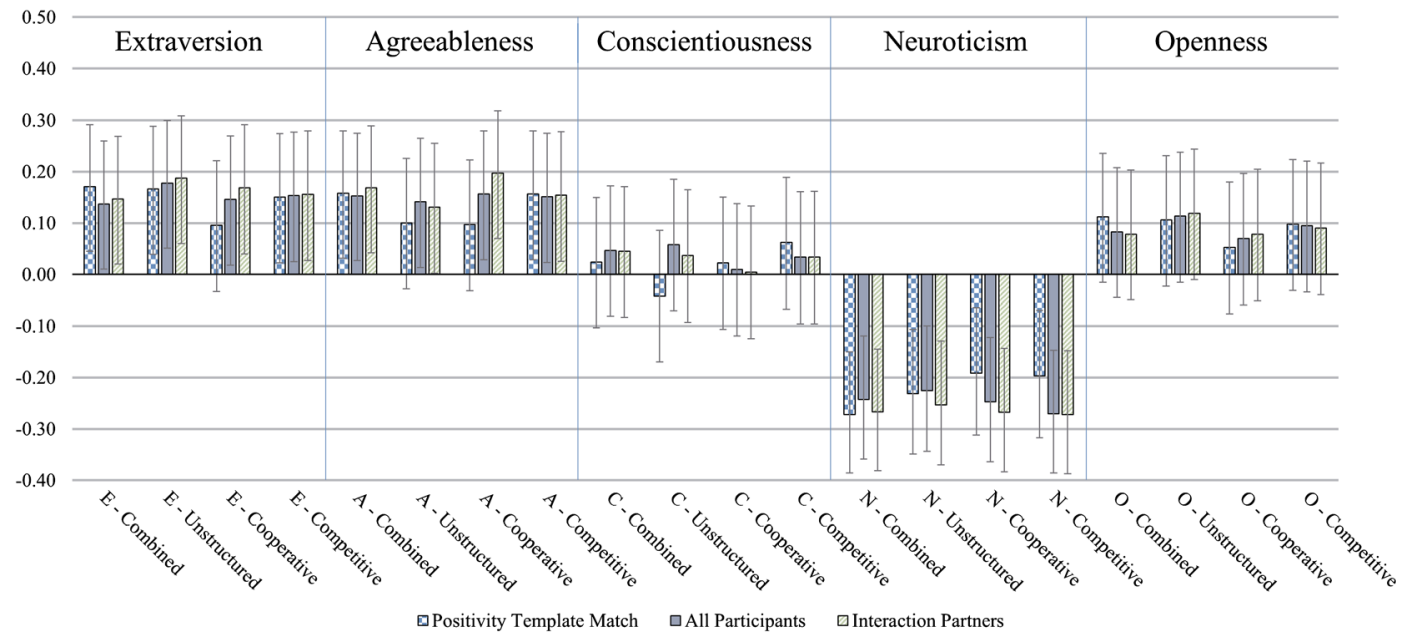

Figure 3. Correlations between Big Five personality traits and positivity of construal are presented for the interactions combined ( $n=239)$ and for each of the unstructured $(n=234)$, cooperative $(n=233)$ and competitive $(n=233)$ interactions. 'Positivity Template Match' refers to the calculation of positivity of construal in which a participant's construal of a situation was compared with the positivity template, 'All Participants' refers to the relationship between positivity and personality after partialling out normativity calculated in relation to all participants and 'Interaction Partners' refers to the relationship between positivity and personality after partialling out normativity calculated in relation to interaction partners. Ninety-five per cent confidence intervals are shown.

was calculated in relation to all participants in the same situation $[r(237)=.41, p<.01,95 \%$ CI $[0.30,0.51]]$ or to interaction partners $[r(237)=.33, p<.01,95 \%$ CI $[0.21$, 0.44]]. Positivity and normativity also showed a similar pattern of correlations with the measure of social outcomes. Combined across visits, normativity of construal and social outcomes was significantly related, whether normativity was calculated in relation to all participants in the same situation $[r(237)=.18, p<.01,95 \%$ CI $[0.06,0.30]]$ or to interaction partners $[r(237)=.18, p<.01,95 \%$ CI $[0.05$, $0.30]$, and this pattern of results was relatively stable for each visit (Figure 4). Combined across visits, the relationship between positivity of construal and social outcomes approached conventional significance, $r(237)=.13, p=.05$, $95 \%$ CI $[0.00,0.25]$, but not when normativity was partialled out [when partialled in relation to all participants, $r$ (236)
$=.06, p=.38,95 \% \mathrm{CI}[-0.07,0.18]$; when partialled in relation to interaction partners, $r(236)=.07, p=.26,95 \% \mathrm{CI}$ $[-0.05,0.20]]$, and this pattern was relatively stable for each visit (Figure 5). Although the partialled correlations were smaller, they were still consistently in the same direction across the three sessions, suggesting that positive situational construal, over and above normativity, may be consequential. Taken together, these results provide partial support for our third hypothesis: Participants who construed their situations normatively and positively tended to experience better social outcomes.

\section{Hypothesis 4: Situational construal as mediator}

The relationships among personality, situational construal and social outcomes were generally small, but given our interest in

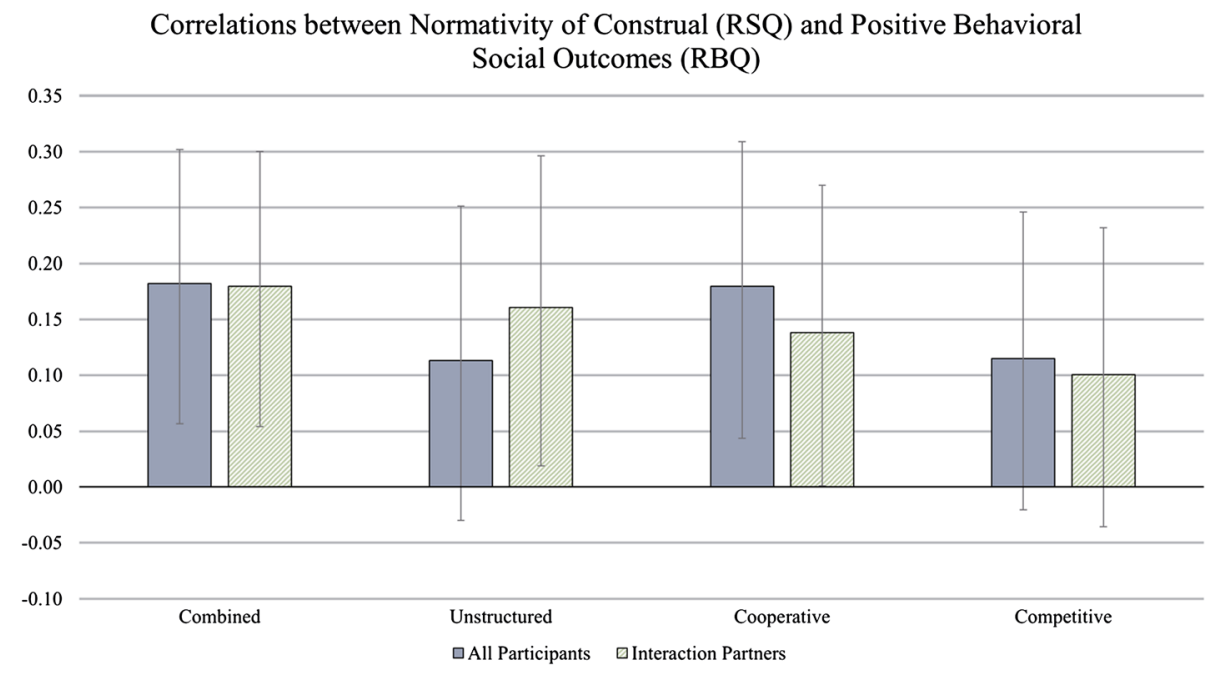

Figure 4. Correlations between normativity of construal and social outcomes are presented for the interactions combined ( $n=239)$ and for each of the unstructured $(n=190)$, cooperative $(n=205)$ and competitive $(n=211)$ interactions. Normativity is calculated both in relation to all participants in the same situation and in relation to each participant's two partners in each triadic interaction. Ninety-five per cent confidence intervals are represented in the figure. 


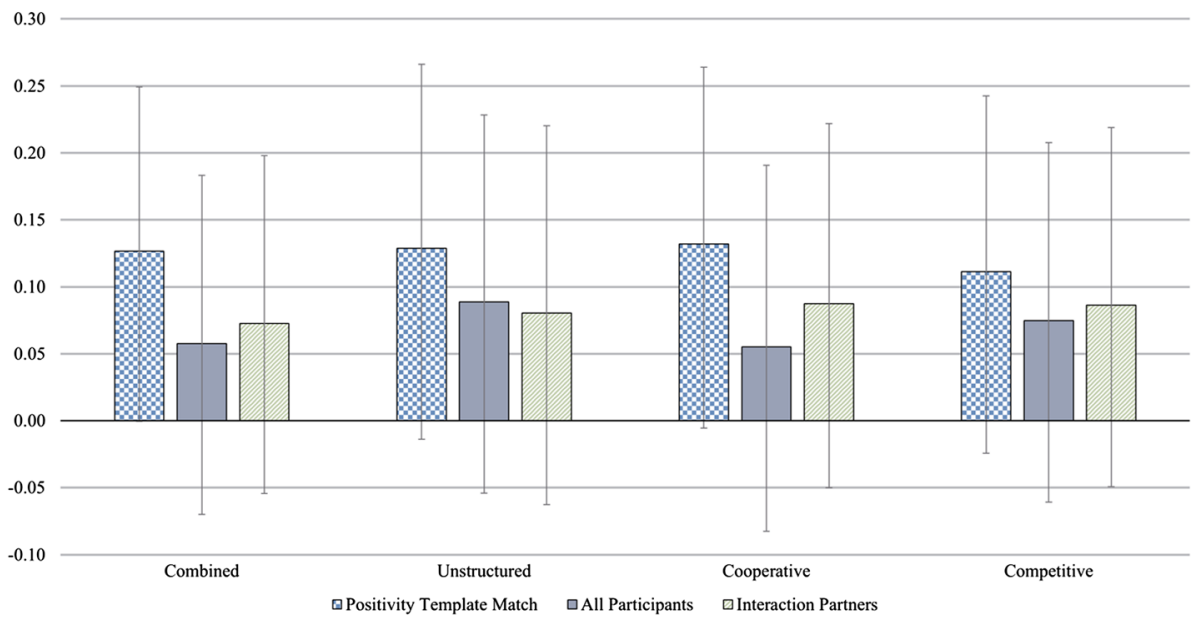

Figure 5. Correlations between positivity of construal and social outcomes are presented for the interactions combined $(n=239)$ and for each of the unstructured $(n=190)$, cooperative $(n=205)$ and competitive $(n=211)$ interactions. 'Positivity Template Match' refers to the calculation of positivity of construal in which a participant's construal of a situation was compared with the positivity template, 'All Participants' refers to the relationship between positivity and personality after partialling out normativity calculated in relation to all participants and 'Interaction Partners' refers to the relationship between positivity and personality after partialling out normativity calculated in relation to interaction partners. Ninety-five per cent confidence intervals are shown.

assessing the possible mediating role that situational construal plays in the relationships between personality and social outcomes, we ran exploratory mediation analyses. The structure of these analyses is shown in Figure 6. Mediation would be demonstrated by significant direct relationships between personality and situational construal, significant direct relationships between the situational construal and social outcomes and less significant relationships between the personality and social outcomes after controlling for situational construal. The mediation results, shown in Table 1, do not show that situational construal mediates the relationship between personality and social outcomes. However, the analyses do suggest that construing situations normatively, but not necessarily positively, is related to social outcomes over and above the influence of personality.

\section{DISCUSSION}

The present study explored the relationships among personality, situational construal and social outcomes using

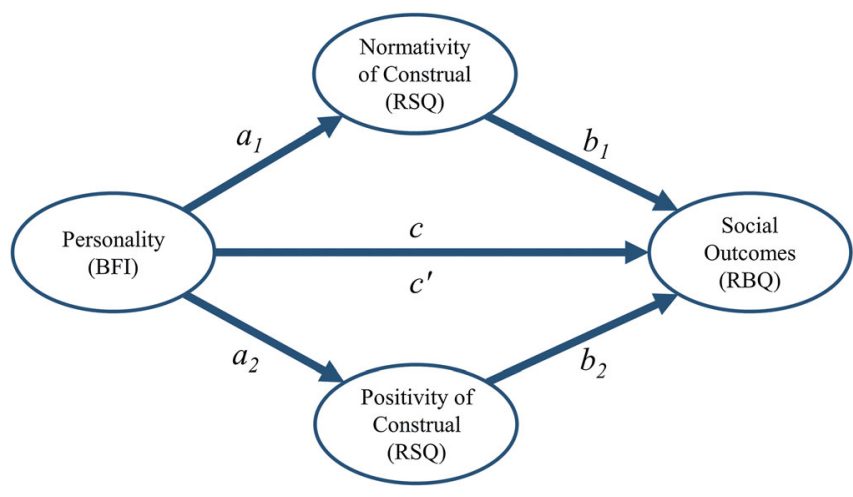

Figure 6. Structure of the mediation analysis reported in Table 1. BFI, Big Five Inventory; RBQ, Riverside Behavioral Q-sort; RSQ, Riverside Situational Q-sort. multiple methods and sources of information. Three of our four hypotheses were generally supported. First, personality, specifically the traits of extraversion, agreeableness, openness and neuroticism (negatively), was related to social outcomes as rated by independent observers. This was true across three distinct lab interactions, with unique partners at each interaction. These findings are consistent with previous research and help to validate the social outcomes measure as well as the notion that participants, in conjunction with their personality, were behaving in these lab contexts as they would more generally.

Second, personality was related to situational construal such that extraversion, agreeableness and openness were associated with construing situations more positively, whereas neuroticism was associated with construing situations more negatively. While these relationships only occasionally reached conventional significance, within each of the Big Five traits, they were generally consistent in direction and magnitude across the three interactions. In addition, normativity and positivity of construal were related such that those who construed their situations normatively also tended to construe these situations positively. This could suggest either that most people construed these situations positively or that these situations were for the most part, in fact, positive.

Third, normativity and (to a lesser extent) positivity of construal were related to social outcomes, such that construing situations normatively or positively was associated with more positive social outcomes, above and beyond what could be explained by personality alone, suggesting that the manner by which situations are construed has bearing on our social success, above the effect of personality. Simply put, seeing situations as others see them, with a positive lens, is associated with social success.

Our fourth hypothesis was not supported by the present data. Although personality is related to social 
Table 1. Standardized mediation coefficients

\begin{tabular}{|c|c|c|c|c|c|c|}
\hline & $a 1$ & $a 2$ & $b 1$ & $b 2$ & $c^{\prime}$ & Bias-corrected $95 \%$ confidence interval \\
\hline \multicolumn{7}{|c|}{ Extraversion $(c=.45 * *)$} \\
\hline Norm $1 \times$ Pos & $.11^{\dagger}$ & $.17 * *$ & $.13^{*}$ & .00 & $.43 * *$ & {$[-0.01,0.05]$} \\
\hline Norm $2 \times$ Pos & .10 & $.17 * *$ & $.13^{*}$ & .01 & $.43 * *$ & {$[-0.01,0.05]$} \\
\hline \multicolumn{7}{|c|}{ Agreeableness $\left(c=.18^{* *}\right)$} \\
\hline Norm $1 \times$ Pos & .04 & $.16^{*}$ & $.16^{*}$ & .03 & $.16^{*}$ & {$[-0.02,0.05]$} \\
\hline Norm $2 \times$ Pos & .00 & $.16^{*}$ & $.17 * *$ & .05 & $.17 * *$ & {$[-0.03,0.04]$} \\
\hline \multicolumn{7}{|c|}{ Conscientiousness $(c=.04)$} \\
\hline Norm $1 \times$ Pos & -.05 & .02 & $.16^{*}$ & .06 & .05 & {$[-0.04,0.02]$} \\
\hline Norm $2 \times$ Pos & -.06 & .02 & $.16^{*}$ & .07 & .05 & {$[-0.05,0.02]$} \\
\hline \multicolumn{7}{|c|}{ Neuroticism $\left(c=-.13^{*}\right)$} \\
\hline Norm $1 \times$ Pos & $-.13 *$ & $-.27 * *$ & $.15^{*}$ & .04 & -.10 & {$[-0.08,0.01]$} \\
\hline Norm $2 \times$ Pos & -.06 & $-.27 * *$ & $.16^{*}$ & .05 & -.11 & {$[-0.07,0.02]$} \\
\hline \multicolumn{7}{|c|}{ Openness $\left(c=.12^{\dagger}\right)$} \\
\hline Norm $1 \times$ Pos & .09 & $.11^{\dagger}$ & $.15^{*}$ & .05 & .10 & {$[0.00,0.06]$} \\
\hline Norm $2 \times$ Pos & $.12^{\dagger}$ & $.11^{\dagger}$ & $.15^{*}$ & .07 & .09 & {$[0.00,0.07]$} \\
\hline
\end{tabular}

Note: Norm1, 'All Participants'; Norm2, 'Interaction Partners'; Pos, 'Positivity Template Match'. See Figure 6 for the structure of this analysis. N=239. ${ }^{\dagger} p<.10,{ }^{*} p<.05, * * p<.01$.

outcomes and to construal and construal is related to social outcomes, mediation analyses did not confirm that construal mediated the relationships between personality and social outcomes.

Despite this last-mentioned outcome, two features of the present work evoke some confidence in our other conclusions. The first feature is the complex method by which independent data were collected. Participants completed four visits to the lab, each spaced roughly 1 week apart, in order to describe their personality, participate in three different interactions with two different partners each time and describe their construal of each situation immediately after the interaction. Furthermore, research assistants viewed these interactions and provided independent ratings of behavioural social outcomes. Ratings of each variable of interest were either captured by a different assessment method (i.e. Likert-type versus Q-sort) or source of data (i.e. self-ratings, other-ratings and self-ratings as compared with peer ratings or a template), mitigating concerns over shared method variance.

The second feature is the consistency of the findings across three separate situations, each occurring about a week apart. The three situations were designed to be distinct from one another (i.e. unstructured, cooperative and competitive interactions), and participants were paired with different interaction partners each time. Despite the differences among these situations, we see recognizably the same pattern of results, in both magnitude and direction, in each of them. Personality is reliably related to construal and social outcomes, and construal is reliably related to social outcomes. Although the individual effects are far from large, the influences of even seemingly 'weak' effects can accumulate over time and numerous occasions to have important consequences for life outcomes (Abelson, 1985; Greenwald, Banaji, \& Nosek, in press, 2015).

This work has several limitations that must be acknowledged. First, as mentioned, the relationships between situational construal and the personality and social outcomes variables were generally small. Three accounts can be offered as to why. First, situational construal can be defined in numerous ways; in fact, every manner of defining situations implies a distinctive manner of defining construal. In the present study, we considered normativity and valence but just as likely could have considered the extent to which participants construed situations as relevant to their motives (e.g. Morse, Neel, Todd, \& Funder, in press) or as opportunities to express their personality (e.g. ten Berge \& De Raad, 1999, 2001, 2002). Perhaps an amalgamation of the various perspectives on construal would elicit larger effects, but the combination of methods for assessing construal would be a complicated endeavour requiring sufficient theoretical rationale and statistical development. Second, personality and social outcomes can be defined and measured in multiple ways. Perhaps person variables aside from the Big Five, or beyond traits more generally (e.g. motives, values and personal narratives), and social outcomes aside from peer ratings of behaviour are more strongly related to situational construal, and further research should explore this possibility. Third, consideration of other mediators might bolster the understanding of the relationships between personality and social outcomes. For example, the general and consistent effect that an individual has on others' emotions, termed affective presence, has been found to mediate the relationship between likability and romantic interest from others (Berrios, Totterdell, \& Niven, 2015). In sum, further research considering other possible mediators may further illuminate the process by which personality is related to various social outcomes.

A second limitation of the present work is that the situations occurred in a lab setting. Constraining the situations to the lab allowed us to observe and record what happened, providing much more detail as well as more objectivity than self-reports ever could. This approach also eliminated concern that different participants would naturally select certain situations that are more or less relevant to social outcomes. However, the lab situations may have reduced the effects of construal because they were obviously less involving and less consequential than interactions in daily life. This trade-off is inevitable, but 
future work should explore the effects of construal in naturally occurring situations that are less constrained and more consequential.

In addition to addressing these limitations, future research should continue to explore the relationships between personality and social outcomes, and possible mediating variables, in order to contribute to our understanding of the processes that lead from personality to social consequences. There is a long road yet to travel, but we believe that the research reported in this article, along with the others in this special issue, moves several steps in the right direction.

\section{ACKNOWLEDGEMENTS}

This research was supported by the National Science Foundation grant BNS BCS-0642243. Any opinions, findings and conclusions or recommendations expressed in this material are those of the individual researchers and do not necessarily reflect the views of the National Science Foundation.

We would like to thank Brandon Wales for statistical insights, Erica Baranski for thoughtful discussions and reviewers for helpful comments on an earlier draft. Additionally, we thank the many research assistants who contributed to this work through data collection and behaviour coding.

\section{REFERENCES}

Abelson, R. P. (1985). A variance explanation paradox: When a little is a lot. Psychological Bulletin, 97, 129-133. DOI: 10.1037/ 0033-2909.97.1.129

Anderson, C., John, O. P., Keltner, D., \& Kring, A. M. (2001). Who attains social status? Effects of personality and physical attractiveness in social groups. Journal of Personality and Social Psychology, 81, 116-132. DOI: 10.1037/0022-3514.81.1.116

Arnulf J. K., Larsen K. R., Martinsen Ø. L., \& Bong, C. H. (2014). Predicting survey responses: How and why semantics shape survey statistics on organizational behaviour. PLOS ONE 9(9): e106361. DOI: 10.1371/journal.pone.0106361

Back, M. D., Schmukle, S. C., \& Egloff, B. (2011). A closer look at first sight: Social relations lens model analysis of personality and interpersonal attraction at zero acquaintance. European Journal of Personality, 25, 225-238. DOI: 10.1002/per.790

Baumeister, R. F., Vohs, K. D., \& Funder, D. C. (2007). Psychology as the science of self-reports and finger movements. Whatever happened to actual behavior? Perspectives on Psychological Science, 2, 396-403.

Berrios, R., Totterdell, P., \& Niven, K. (2015). Why do you make us feel good? Correlates and interpersonal consequences of affective presence in speed-dating. European Journal of Personality, 29, 72-82.

Berry, D. S., \& Hansen, J. S. (1996). Positive affect, negative affect, and social interaction. Journal of Personality and Social Psychology, 71, 796-809. DOI: 10.1037/0022-3514.71.4.796

Biesanz, J. C. (2010). The social accuracy model of interpersonal perception: Assessing individual differences in perceptive and expressive accuracy. Multivariate Behavioral Research, 45, 853-885.

Greenwald, A. G., Banaji, M. R., \& Nosek, B. A. (in press, 2015). Statistically small effects of the implicit association test can have societally large effects. Journal of Personality and Social Psychology. DOI: 10.1037/pspa0000016
Finn, C., Mitte, K., \& Neyer, F. J. (2013). The relationship-specific interpretation bias mediates the link between neuroticism and satisfaction in couples. European Journal of Personality, 27, 200-212. DOI: $10.1002 /$ per. 1862

Funder, D. C. (2013). Taking situations seriously. Honolulu: Division 8 Presidential Address, American Psychological Association.

Funder, D. C., Furr, R. M., \& Colvin, C. R. (2000). The Riverside Behavioral Q-sort: A tool for the description of social behavior. Journal of Personality, 68, 451-489.

Furr, R. M. (2008). A framework for profile similarity: Integrating similarity, normativeness, and distinctiveness. Journal of Personality, 76, 1267-1316.

Hill, P. L., Turiano, N. A., Mroczek, D. K., \& Roberts, B. W. (2012). Examining concurrent and longitudinal relations between personality traits and social well-being in adulthood. Social Psychological and Personality Science, 3, 698-705. DOI: $10.1177 / 1948550611433888$

Ilmarinen, V., Vainikainen, M., Verkasalo, M., \& Lönnqvist, J. (2015). Why are extraverts more popular? Oral fluency mediates the effect of extraversion on popularity in middle childhood. European Journal of Personality, 29, 138-151.

John, O. P., Naumann, L. P., \& Soto, C. J. (2008). Paradigm shift to the integrative Big-Five trait taxonomy: History, measurement, and conceptual issues. In O. P. John, R. W. Robins, \& L. A. Pervin (Eds.), Handbook of personality: Theory and research. (pp. 114-158). New York, NY: Guilford Press.

John, O. P., Donahue, E. M., \& Kentle, R. L. (1991). The Big Five Inventory-Versions $4 a$ and 54. Berkeley, CA: University of California, Berkeley, Institute of Personality and Social Research.

Kelly, H. H. (1950). The warm-cold variable in first impressions of persons. Journal of Personality, 18, 431-439.

Kenny, D. A. (1994). Interpersonal perception: A social relations analysis. New York: Guilford Press.

Morse, P. J., Neel, R., Todd, E., \& Funder, D. C. (in press). Renovating situation taxonomies: Exploring the construction and content of fundamental motive situation types. Journal of Personality.

Morse, P. J., Sweeny, K., \& Legg, A. M. (2015). A situational construal approach to healthcare experiences. Manuscript submitted for publication.

Murray, H. A. (1938). Explorations in personality. Oxford, England: Oxford University Press.

Ozer, D. J., \& Benet-Martínez, V. (2006). Personality and the prediction of consequential outcomes. Annual Review of Psychology, 57, 401-421. DOI: 10.1146/annurev.psych.57.102904. 190127

Paunonen, S. V. (2003). Big Five factors of personality and replicated predictions of behavior. Journal of Personality and Social Psychology, 84, 411-424. DOI: 10.1037/0022-3514. 84.2.411

Roberts, B. W., Kuncel, N. R., Shiner, R., Caspi, A., \& Goldberg, L. R. (2007). The power of personality: The comparative validity of personality traits, socioeconomic status, and cognitive ability for predicting important life outcomes. Perspectives on Psychological Science, 2, 313-345. DOI: 10.1111/j.17456916.2007.00047.x

Schaffhuser, K., Allemand, M., \& Martin, M. (2014). Personality traits and relationship satisfaction in intimate couples: Three perspectives on personality. European Journal of Personality, 28, 120-133. DOI: 10.1002/per.1948

Serfass, D. G., \& Sherman, R. A. (2013). Personality and perceptions of situations from the Thematic Apperception Test. Journal of Research in Personality, 47, 708-718. DOI: 10.1016/j. jrp.2013.06.007

Sherman, R. A., Nave, C. S., \& Funder, D. C. (2013). Situational construal is related to personality and gender. Journal of Research in Personality, 47, 1-14. DOI: 10.1016/j. jrp.2012.10.008

Stopfer, J. M., Egloff, B., Nestler, S., \& Back, M. D. (2013). Being popular in online social networks: How agentic, communal, and 
creativity traits relate to judgments of status and liking. Journal of Research in Personality, 47, 592-598. DOI: 10.1016/j. jrp.2013.05.005

Ten Berge, M. A., \& De Raad, B. (1999). Taxonomies of situations from a trait psychological perspective: A review. European Journal of Personality, 13, 337-360. DOI: 10.1002/(SICI)1099-0984 (199909/10)13:5<337::AID-PER363>3.0.CO;2-F

Ten Berge, M. A., \& De Raad, B. (2001). The construction of a joint taxonomy of traits and situations. European Journal of Personality, 15, 253-276. DOI: 10.1002/per.410
Ten Berge, M. A., \& De Raad, B. (2002). The structure of situations from a personality perspective. European Journal of Personality, 16, 81-102. DOI: 10.1002/per.435

Vater, A., \& Schröder-Abé, M. (2015). Explaining the link between personality and relationship satisfaction: Emotion regulation and interpersonal behavior in conflict discussions. European Journal of Personality, 29, 201-215.

Wagerman, S. A., \& Funder, D. C. (2009). Situations. In P. J. Corr \& G. Matthews (Eds.), Cambridge handbook of personality (pp. 27-42). Cambridge: Cambridge University Press. 